\title{
Role of coprophagy in the cecal microbiome development of an herbivorous bird Japanese rock ptarmigan
}

\author{
Atsushi KOBAYASHI ${ }^{1)}$, Sayaka TSUCHIDA ${ }^{2,3)}$, Atsushi UEDA ${ }^{4)}$, Takuji YAMADA ${ }^{4)}$, \\ Koichi MURATA ${ }^{5)}$, Hiroshi NAKAMURA ${ }^{6)}$ and Kazunari USHIDA ${ }^{2,3) *}$ \\ 1)Faculty of Science, Toho University, Chiba 274-8510, Japan \\ ${ }^{2)}$ Graduate School of Life and Environmental Sciences, Kyoto Prefectural University, Kyoto 606-8522, Japan \\ ${ }^{3)}$ Chubu University, Academy of Emerging Sciences, Kasugai, Aichi 487-8501, Japan \\ 4)Department of Life Science and Technology, School of Life Science and Technology, Tokyo Institute of \\ Technology, Tokyo 152-8550, Japan \\ ${ }^{5)}$ Faculty of Bioresource Sciences, Nihon University, Kanagawa 252-0800, Japan \\ ${ }^{6)}$ General Foundation Hiroshi Nakamura International Institute for Ornithology, Nagano 380-0934, Japan
}

\section{J. Vet. Med. Sci. \\ 81(9): 1389-1399, 2019}

doi: 10.1292/jvms.19-0014

Received: 9 January 2019

Accepted: 15 July 2019

Advanced Epub: 12 August 2019
ABSTRACT. The transgenerational maintenance of symbiotic microbes that benefit host nutrition and health is evolutionarily advantageous. In some vertebrate lineages, coprophagy is used as a strategy for effectively transmitting microbes across generations. However, this strategy has still not been studied in birds. Accordingly, the aim of the present study was to evaluate the role of maternal cecal feces consumption by Japanese rock ptarmigan (Lagopus muta japonica) chicks as a strategy for acquiring essential gut microbes. Both the duration of coprophagy behavior by the chicks and the development process of the chick cecal microbiome ( $n=20$ one- to three-week-old chicks, from three broods) were investigated. In all three broods, coprophagy behavior was only observed from 3 to 18 days of age. Furthermore, there was no significant difference in the number of bacterial operational taxonomic units (OTUs) in 1-week-old chicks ( $n=651)$ and adults $(n=609)$, and most of the main OTUs observed in the adults were already present in the 1-week-old chicks. These results indicate that, in this precocial bird species, coprophagy may contribute to the early establishment of cecal bacteria that are essential for food digestion and, thus, chick survival. In fact, Japanese rock ptarmigan chicks consume the same food as their hens from the time of hatching. This behavior may have applications to ex-situ conservation.

KEY WORDS: coprophagy, gut microbiome development, herbivorous bird, microbiome transmission

Coprophagy, which is the consumption of feces, includes the consumption of feces from other species (heterospecific coprophagy), from other individuals of the same species (allocoprophagy), or from one's self (autocoprophagy) [22] and has been observed in a variety of animal groups, including vertebrates [14, 23, 44]. In herbivorous mammals, such as rodents, autocoprophagy is considered an adaptive behavior for recycling vitamins, minerals, amino acids, trace elements, and other nutrients that are excreted in the feces. However, heterospecific coprophagy and allocoprophagy are sometimes considered non-feeding behaviors that inoculate the gut with the bacteria and protozoa of other individuals [11, 13], even if these types of coprophagy also have nutritional significance [22, 36, 44]. Feeding the feces of older individuals to juvenile conspecifics is, in fact, a kind of fecal transplantation that facilitates the coevolution between host species and symbiotic gut bacteria by continuously transmitting the bacteria to subsequent generations. Since gut bacteria contribute to the digestion of fiber and degradation of toxic secondary compounds from the plants that are consumed by herbivores [19,31, 37, 60, 63], allocoprophagy is often observed in herbivorous mammals [4, 37]. Like mammals, birds represent a diverse and evolutionarily successful lineage and occupy a wide range of food niches throughout the world [16]. However, herbivory is a rare strategy in birds (only 3\% of species) [34, 35]. This may reflect the challenges of flight since large and heavy digestive tracts are needed to digest fibrous and toxic foods [8]. The main fermentation chamber of plant materials in herbivorous birds, excluding the hoatzin (Opisthocomus hoazin), is the hindgut, which includes a well-developed cecum $[17,28]$. Therefore, herbivorous birds may use a strategy to maintain gut bacteria that is

*Correspondence to: Ushida, K.: k_ushida@isc.chubu.ac.jp (Supplementary material: refer to PMC https://www.ncbi.nlm.nih.gov/pmc/journals/2350/)

(O2019 The Japanese Society of Veterinary Science

This is an open-access article distributed under the terms of the Creative Commons Attribution Non-Commercial No Derivatives (by-nc-nd) License. (CC-BY-NC-ND 4.0: https://creativecommons.org/licenses/by-nc-nd/4.0/) 
similar to that used by herbivorous mammals. However, little is known about the mechanisms by which essential gut microbes are maintained in avian hosts over multiple generations.

The Japanese rock ptarmigan (JRP) Lagopus muta japonica is a domestic endangered species that has experienced population declines over the last 40 years [12]. The bird is an isolated subspecies of rock ptarmigan (L. muta), which is a typical herbivorous hindgut-fermenter that is characterized by a pair of well-developed ceca [41, 45]. As in leporids [43], rock ptarmigans produce two types of feces: hard, fibrotic feces ("rectal feces") and soft, pasty feces ("cecal feces"). It is easy to distinguish these two types of feces by visual examination. The mechanisms by which these feces types are formed remains unknown, but the system seems to be similar to that described in rabbits [43], in which cecal feces are formed in the ceca and are rich in cecal bacteria and their metabolites $[39,43]$. The main food sources of the JRP include alpine plants, such as crowberry (Empetrum nigrum var. japonica), cowberry (Vaccinium vitis-idaea), yellow-flowered rhododendron (Rhododendron aureum), and Aconogonon weyrichii var. alpinum [29], that contain a variety of chemicals to protect them from herbivory [61]. As such, the bacteria of the bird's ceca are hypothesized to be specialized to the bird's diet. Indeed, at least some anti-herbivore chemicals are reportedly degraded by the cecal bacteria of the JRP $[49,50]$.

Prior to this study, JRP chicks were unintentionally observed to exhibit coprophagy toward the cecal feces of their mothers,

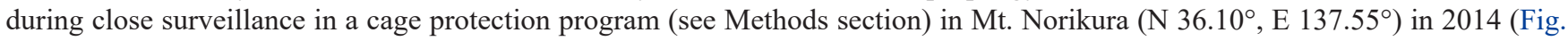
1a-d). Rock ptarmigan hens frequently brood their chicks to warm them, since chicks are incapable of thermoregulating themselves just after hatching [47]. Chicks normally follow their hen after brooding, and in the instance in which coprophagy was observed, 3-d-old chicks were observed to consume the freshly defecated cecal feces of their hens (Fig. 1a-c), leaving behind distinctive peck traces on the surface of the feces (Fig. 1d).

As mentioned above, allocoprophagy, especially toward the cecal feces of mothers, may mediate the transmission of essential gut microbiota from older generations to young chicks. Similar behavior has been reported in the koala (Phascolarctos cinereus), where mothers feed a special type of feces to their pups during the weaning period, in order to transmit cecal microbes [37]. Accordingly, the aim of the present study was to test the hypothesis that the coprophagy behavior of JRP chicks facilitates the transgenerational transmission of important cecal microbes. The hypothesis was tested by continuously observing the behavior of chicks after hatching, for up to $23 \mathrm{~d}$, in order to determine the frequency of coprophagy toward their hen's cecal feces. Furthermore, the cecal microbiomes of the chicks were analyzed using high-throughput sequencing (HTS)-based meta 16S rRNA gene analysis, in order to investigate the development of the chick cecal microbiome. Finally, the role of allocoprophagy in the development of the chick cecal microbiome is discussed.
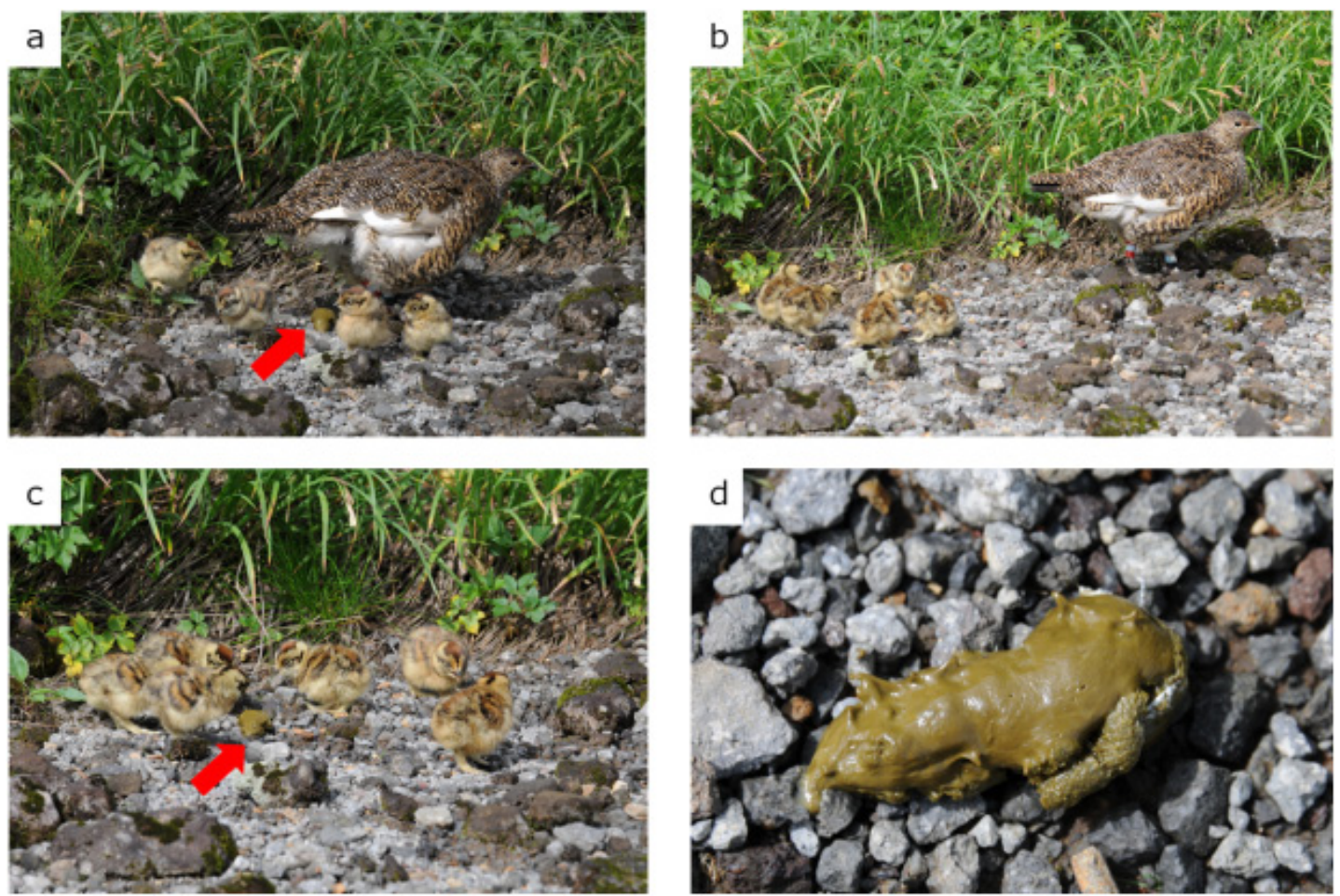

Fig. 1. Coprophagy behavior of Japanese rock ptarmigan chicks. a) Excretion of the cecal feces, just after brooding to warm the body temperature of the chicks. b) congregation of chicks around cecal feces, rather than around the hen. c) Pecking of the hen's cecal feces by chicks. Pecking behavior was observed for all chicks. d) Cecal feces left behind after pecking by the chicks. Traces of pecking are seen on the surface of the feces. Red arrows indicate the cecal feces of hens. 


\section{MATERIALS AND METHODS}

\section{Behavior observation and feces collection}

Behavioral observations and the collection of cecal feces were conducted using individuals from an in-situ conservation program that involved temporary cage protection, under the approval of the Ministry of Environment, in order to protect young chicks from predation and severe monsoon climate conditions. In 2016, three cages were established near a mountain lodge (2900 a.s.1.) on Mt. Kita, which is located in the Southern Japanese Alps, where the extinction of the JRP is of highest concern. We introduced three wild families to the cages (one hen and brood to each cage) as soon as families were identified in the field. A total of 20 chicks and three hens were included in the study.

The protection periods for the first, second, and third cages were from 27 June to 19 July, 2016 (23 days; chicks ranged from 1 to 23 days old), from 1-19 July, 2016 (19 days; chicks ranged from 2 to 20 days old), and from 1-20 July (20 days; chicks ranged from 1 to 20 days old), respectively. The hatching dates of the chicks in the first cage were observed directly, where those of chicks in the other two cages were estimated by body size. The hens and chicks grazed freely outside the cages during the daytime ( $\geq 2$ times each day, for $\leq 2 \mathrm{hr}$ under observation), except for in cases of poor weather (heavy rain or cold, windy conditions). The hens and chicks were also fed wild plants (e.g., Vaccinium ovalifolium, Stellaria nipponica, Oxytropis japonica, Aconogonon weyrichii, Bistorta vivipara), which were collected in alpine areas, and frozen Vaccinium vitis-idaea fruits, which were collected the previous year. The natural food items were selected in accordance with previous field observations (Kobayashi, unpublished data). Mealworms (Tenebrio molitor) were used to replace the natural insects predated by JRPs.

As mentioned above, JRPs produce two types of feces. In the present study, allocoprophagy was recorded when peck traces were observed on the surfaces of the hens' cecal feces in the cages. Pecking by the chicks resulted in very specific markings (Fig. 1d), which were easy to detect on the surfaces of the cecal feces. Furthermore, since neither the auto- nor allocoprophagy of feces by adult rock ptarmigans had been reported in the literature, peck traces were interpreted as intentional coprophagy by chicks (Fig. 1).

Portions of fresh cecal feces were collected from chicks (4- to 22-d-old) during the first, second, and third weeks of cage protection (exact dates are reported in Table S1), and fresh cecal feces were collected from the hens at the beginning and end of the protection period. Details of the sampling procedure are provided below. Cecal feces were collected at $<30$ min after defecation. Both chicks and hens normally defecate both types of feces when they start feeding after sunrise, and collection was performed from as early as 5 a.m. In some cases, cecal feces were also collected under visual observation during foraging. To avoid potential contamination by environmental bacteria, a portion of the cecal feces free from soil was collected using sterile tweezers. Due to differences in the size of the hens and chicks, it was easy to distinguish the feces of the hens and chicks. Since the chicks were not marked using leg bands, cecal feces were not attributed to specific individuals, and in some cases, all the chick feces collected from a single cage were combined as a daily sample, usually because chick feces were too small to yield sufficient amounts of DNA. The collected cecal feces were preserved in sterile storage buffer [21], transported to the laboratory, and stored at $20^{\circ} \mathrm{C}$ for up to a month. The effectiveness of this methodology has been established by previous studies that were conducted under less-controlled conditions [27].

\section{DNA extraction and $16 S$ rRNA gene deep sequencing}

Total DNA was extracted from stored fecal samples using a tissue DNA kit (QuickGene Mini80 system; Kurabo, Tokyo, Japan), as reported previously [55]. Briefly, the feces were recovered from the storage buffer by centrifugation and were washed using phosphate-buffered saline (PBS) to remove residual buffer solution. A portion of a fecal pellet (20-50 mg) was suspended in tissuelysis buffer (MDT) from the kit, along with glass beads. After bead disruption, DNA was extracted following the standard protocol of the kit's manufacturer. The quantity and quality of the resulting DNA solutions were assessed using a Nano Drop ND-1000 (Thermo Fisher Scientific, Waltham, MA, U.S.A.) and a Quant-iT dsDNA HS assay kit, with a Qubit Fluorometer (Invitrogen, Carlsbad, CA, U.S.A.). No DNA degradation was observed, and all the samples successfully passed a DNA quality check before library construction.

The construction and sequencing of 16S rRNA gene amplicon libraries were performed at BGI Japan (Kobe, Japan) using the Illumina MiSeq platform as reported previously [33]. Briefly, the V3/V4 region of the 16S rRNA gene was amplified using specific primers: 341F (ACTCCTACGGGAGGCAGCAG) and 806R (GGACTACHVGGGTWTCTAAT). The qualified libraries subject to paired-end sequencing using the MiSeq System, with sequencing strategy PE300 [33]. After sequencing, low-quality reads were removed by eliminating reads with adapter sequences, $>10 \%$ unknown bases, or $>50 \%$ low-quality bases (with quality values of $<10$ ). Forward and reverse reads of the paired-end library were then merged using USEARCH (version 8.0.1517) [9], and merged reads that (1) contained ambiguous nucleotides or (2) were mapped to the PhiX genome sequence, using Bowtie 2 (version 2.2.3) [32], were eliminated. Finally, high-quality reads without forward or reverse primer sequences were obtained by eliminated reads that (1) contained $<250$ or $>450$ nt or (2) were associated with low $(<25)$ mean Phred quality scores, as calculated by the Illumina MiSeq sequencer. Sequence clustering of the high-quality reads was conducted using UCLUST (version 8.0.1517), with identity $>97 \%$ and query and reference coverage $>80 \%$ [9]. Chimeric OTUs were detected and removed if assigned to chimeras by both (1) UCHIME (version 6.0.307) [10], using reference mode to search against the reference gold database (http://drive5.com/uchime/ gold.fa), and (2) UCHIME de novo mode search. The taxonomic assignment the high-quality reads was performed using RDP Classifier (version 2.12) [62]. OTUs that were represented by less than three reads were eliminated from the dataset, owing to their insignificant contribution to the total reads (on average, $86.4 \%$ of reads remained after the rare OTUs were eliminated).

The mean number of bacterial OTUs and Shannon-Wiener diversity index were calculated for both the chicks, at every week 
after hatching, and adults (hens) to evaluate the alpha diversity of the cecal microbiome, and PERMANOVA was performed to evaluate the similarity of the OTU-level microbiomes from different age groups and families.

The OTUs were classified according to the detection pattern. When OTUs were detected in all growth stages, the increasing or decreasing trends of their prevalence were identified. If the fold-change observed for a particular OTU (highest proportion value was divided by the lowest proportion value) was less than ten times, the OTU was defined as "stable". However, if the prevalence changed by more than ten times between stages, the OTU was defined as "increasing" (i.e., lowest at one week of age and highest in the adult) or "decreasing" (i.e., the highest at 1 week of age and lowest in the adult) with respect to host growth. In addition, some OTUs were observed to sequentially increase and decrease during host growth (higher in 2- or 3-week-old chicks and lower in 1-week-old chicks and adults) or to sequentially decrease and then increase (highest in 1-week-old chicks and adults and lower in 2- or 3-week-old chicks). Statistical analyses were performed using R (version 3.5.1) [40].

\section{Ethics statement}

Fecal sampling was performed in a non-invasive manner. All the sampling methods and access to the JRPs were approved by the Ministry of the Environment (ERTDF 4-1604), and by the Agency for Cultural Affairs and the Ministry of Education, Science, Sport and Culture (27-4-365).

\section{RESULTS}

Pecking traces on the cecal feces of hens were confirmed for all broods. It is worth noting that no pecking traces were observed on the rectal feces of the hens or on the feces of the chicks. Pecking traces on the cecal feces of hens were observed while the chicks were 3-18 days old (Fig. 2), and the chicks were first observed to excrete cecal feces at 4 days after hatching. Therefore, the chicks exhibited coprophagy before excreting cecal feces.

The construction of rarefaction curves indicated that our sequencing effort was not large enough to assess the diversity of cecal bacteria, owing to the detection of single-read OTUs. On average, 30,318 reads ( $\mathrm{n}=27$; range: 11,914-58,668) were obtained after removing the reads corresponding to rare OTUs.

The number of bacterial OTUs detected in the cecal feces of chicks during the first week was similar to that in the cecal feces of the hens (Fig. S1), and there were no significant differences in the number of OTUs detected in the different stages (ANOVA: $\left.\mathrm{F}_{3,23}=1.983, P=0.144\right)$. When the number of OTUs was normalized by total read number, OTU richness tended to increase with host growth. However, significant differences were only detected the OTU richness of the 1- and 3-week-old chicks (Tukey test: $P<0.01$; Fig. 3). The same trends were observed if the rare OTUs ( $<3$ reads) were included in the analysis (Fig. S2).

The alpha diversity of the microbiome increased with host growth (Fig. 4), as shown by the normalized OTU numbers (Fig. 3). However, significant differences in alpha diversity were only detected for the comparison of 1- and 3-week-old chicks (Tukey test: $P<0.01$ ). Age also affected the composition of the cecal microbiome, whereas family did not (PERMANOVA: n=27; age effect, $\mathrm{R}^{2}=0.085, P<0.01$; family effect, $\left.\mathrm{R}^{2}=0.050, P=0.103\right)$.

A total of 431 OTUs (12\% of all OTUs) were common to all growth stages (Fig. 5a) and represented 77 bacterial genera such

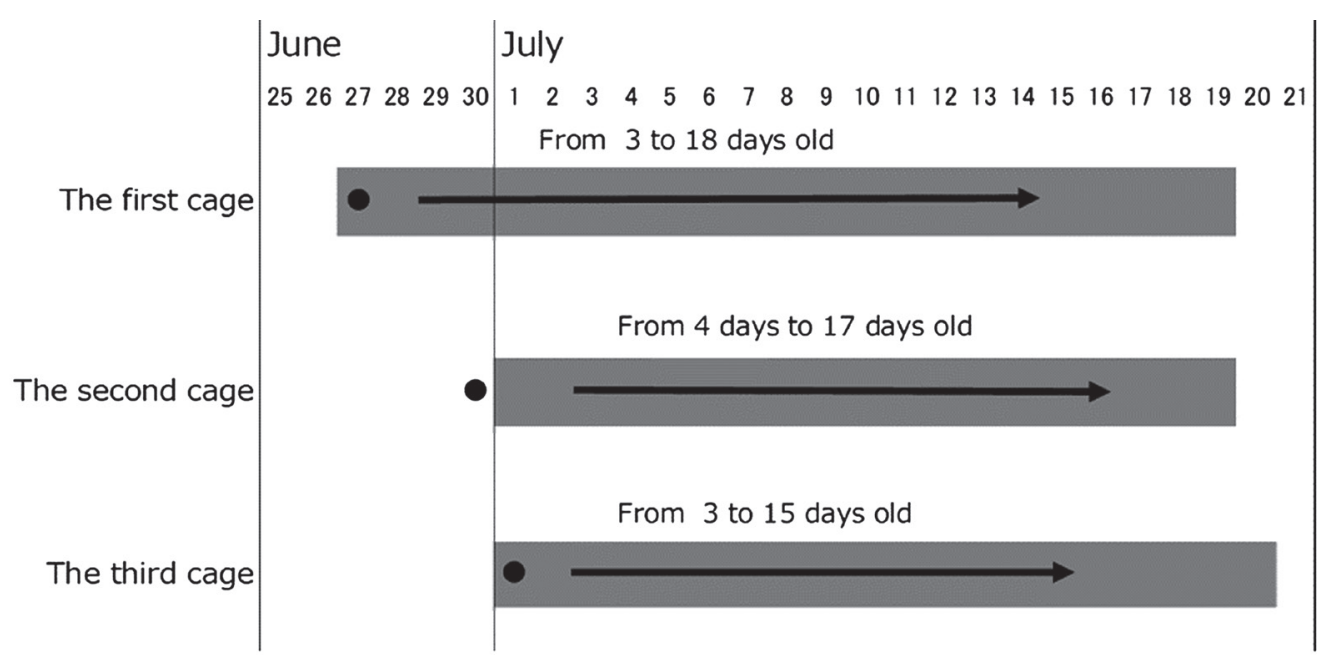

- Hatching date $\square$ Period of protection in cage $\rightarrow$ Period of existence of peck trace on mother's feces

Fig. 2. Periods of cage protection and coprophagy in Japanese rock ptarmigan chicks. Three broods, with their hens, were protected in cages from 27 June to 20 July, 2016. Black dots indicate actual or estimated chick hatching dates. Gray bars indicate the period of cage protection. Black arrows indicate observations of pecking traces on the cecal feces of the hens. Coprophagy started before the first excretion of cecal feces by chicks because cecal feces were not excreted by chicks until they were 4 or 5 days old. Coprophagy ceased by 3 weeks of age in all three broods. 


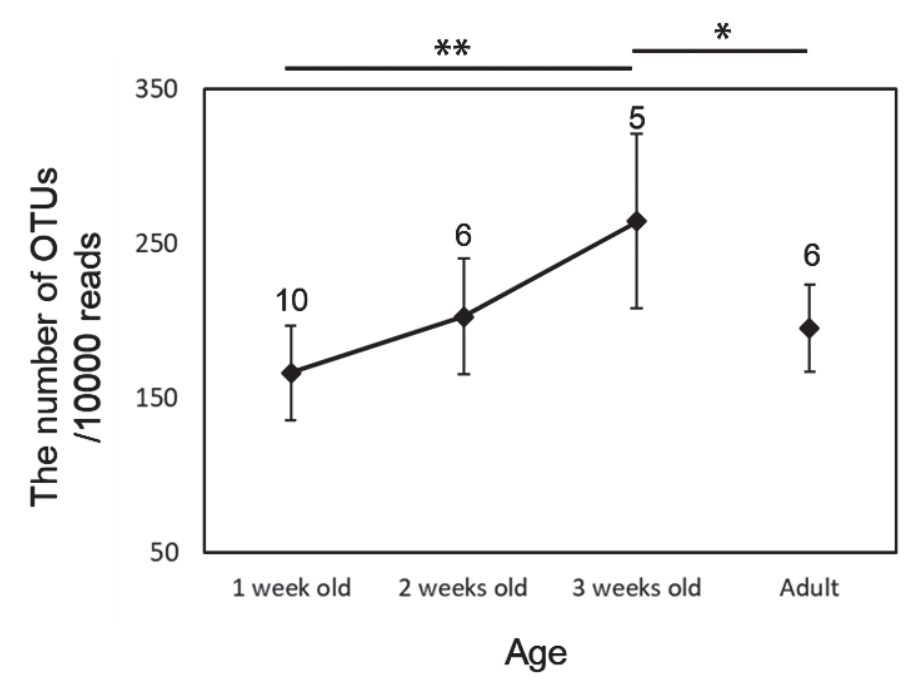

Fig. 3. Normalized abundance of bacterial operational taxonomic units (OTUs) in the cecal microbiomes of Japanese rock ptarmigans. Cecal feces were collected from 1-, 2-, and 3-week-old chicks, as well from their hens. OTU numbers were normalized by total read number, in order to avoid bias from differences in sequencing depth. Error bars indicate standard deviation values. The figures above error bars indicate the sample numbers. $* P<0.05$ between 1 -week-old chicks and adult, ${ }^{* *} P<0.01$ between 1 - and 3-week-old chicks.

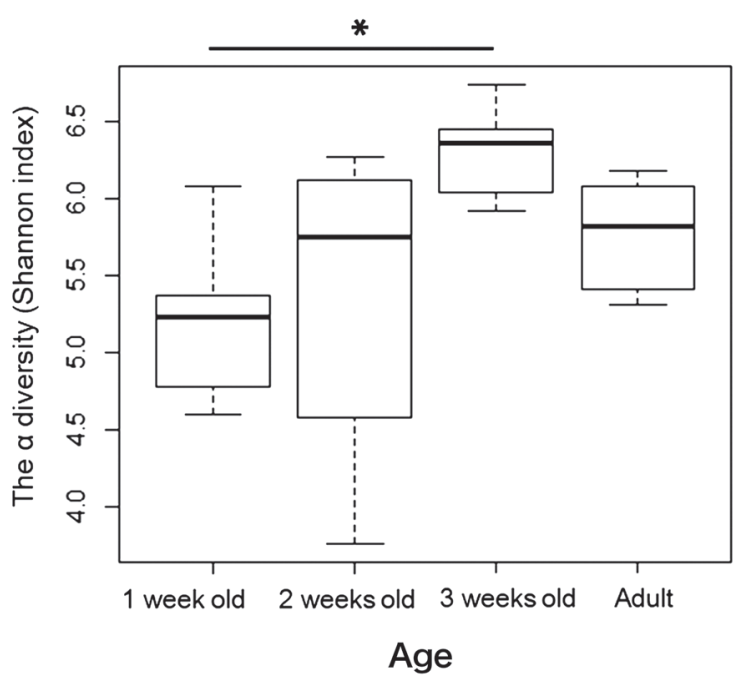

Fig. 4. Effect of age on the development of cecal microbiome alpha diversity in Japanese rock ptarmigans. Cecal feces were collected from 1-, 2-, and 3-week-old chicks, as well from their hens. ${ }^{*} P<0.05$ between 1 - and 3 -weekold chicks.

as Olsenella, Actinomyces, Alkalibaculum, Slackia, Megasphaera, Shuttleworthia, Erysipelotrichaceae incertae sedis, Vallitalea, Robinsoniella, and Defluviitalea (Table S2). The total number of reads attributed to the common OTUs accounted for 93.0, 91.5, 79.1 , and $88.8 \%$ of the reads obtained for 1-, 2-, and 3-week-old chicks and for their hens (Fig. 5b).

The majority of OTUs $(64.0 \%)$ common to all growth stages were stable during host growth (Table 1). For example, Olsenella sp. and Alkalibaculum sp. were consistently listed as some of the most abundant taxa (top three highest proportions), regardless of growth stage. Meanwhile, the remaining OTUs varied with the host's growth: decreasing with growth (7.4\%), increasing with growth $(3.7 \%)$, rising and falling $(13.9 \%)$, or falling and then rising $(10.9 \%)$. In the last category, OTUs that constituted a high proportion of the adult cecal microbiome (e.g., Megasphaera sp. and Vallitalea sp.) were involved.

\section{DISCUSSION}

The allocoprophagy of hen cecal feces by JRP chicks (Fig. 1) was confirmed for all three broods and was observed from a few days after the chicks hatched to about 3 weeks after hatching (Fig. 2). The duration of this period is consistent with previous observations (Fig. 1). Neither allo- nor autocoprophagy has been observed in adult JRPs toward either cecal or rectal feces, despite close observation of the last 10 years, and neither allo- nor autocoprophagy has been observed in chicks toward cecal feces after the age of one month. It is worth noting that coprophagy has not been reported in wild Tetranoids, including grouses and ptarmigan, despite close observation [60]. Indeed, no attention was paid to the coprophagy of ptarmigans in previous research because the frequency of cecal feces excretion by chicks is low and because coprophagy is only exhibited during the very early growth stages, as demonstrated by the present study. The present study is the first work to focus on the coprophagy of herbivorous birds. The cage protection protocol enabled us to exhaustively observe the feces of the hens and behavior of the chicks starting from very early growth stages. Considering that chicks first excrete cecal feces at 4 days of age when raised in captivity (Kobayashi et al. unpublished data), it is likely that the onset of coprophagy toward the hens' cecal feces slightly precedes the excretion of cecal feces by chicks.

Even though the depth of the present study's sequencing was not extensive, the main characteristics of the chick cecal microbiome were determined. The same number of OTUs were detected in the microbiomes of both the youngest chicks $(\leq 1$-weekold) and the hens (Fig. 3), as were the main bacterial OTUs of the hen's cecal microbiome (Fig. 5b). Most of the main adult OTUs were defined as stable (Table 1), meaning that they are acquired during early growth stages and continue to reside in the gut throughout life. Recent studies have reported that some bacteria can be detected in the intestines of bird embryos and newly hatched chicks, but those numbers are negligible $[6,7,18,28]$. Therefore, the OTU richness of the cecal microbiome should be lower in JRP chicks before coprophagy. However, this was difficult to confirm before the first excretion of cecal feces, which occurred after the onset of coprophagy.

Unlike in JRPs, the numbers of bacterial OTUs in the feces of adult altricial species are much higher than those of chicks, even 
a

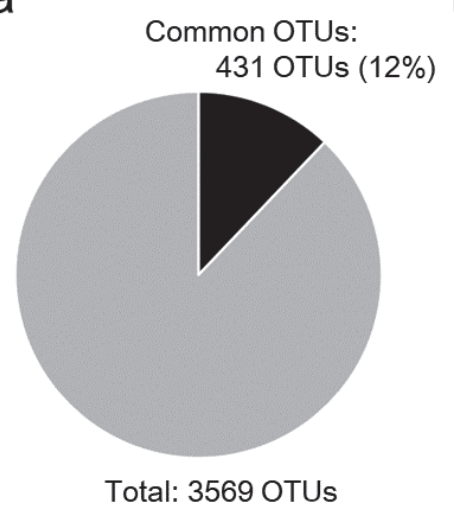

b

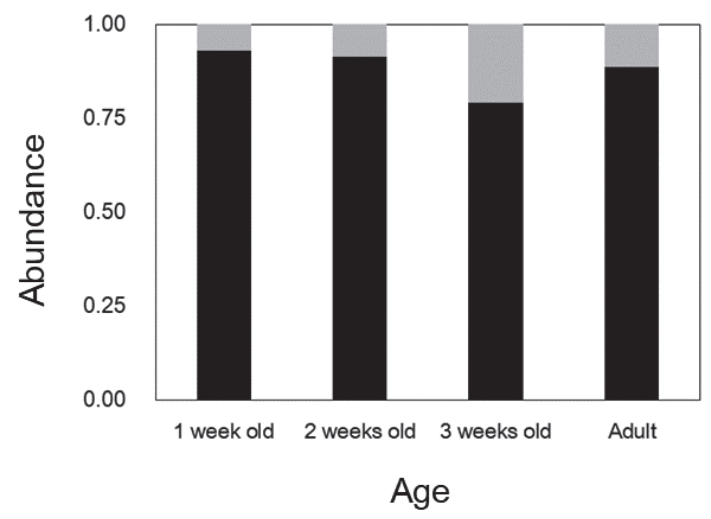

Fig. 5. Effect of age on the abundance of common bacterial operational taxonomic units (OTUs) in Japanese rock ptarmigans. a) Proportion of OTUs attributed to common OTUs. b) Effect of age on the abundance of common OTUs. Black indicates the proportion of common OTUs, and gray indicates the proportion of other OTUs. OTUs represented by less than three reads were omitted from analysis.

at several weeks after hatching [56]. As a result, the dominant OTUs of the species' gut microbiome changes drastically with host growth [56]. Indeed, this phenomenon has also been reported for the chicks of several precocial species that were artificially raised, without contact with their parents $[1,5,58,59]$. These studies demonstrated that the gut microbiomes of these chicks were slow to establish and the chicks did not share the predominant gut bacteria of adult individuals, until at least several weeks after hatching. In contrast, JRP chicks that were raised under cage protection protocol, which allowed the chicks to perform coprophagy toward their hens' cecal feces, shared the major OTUs of the adult cecal microbiome from very early in life.

The predominant bacterial genera detected in the cecal feces of the chicks used in the present study (e.g., Olsenella, Actinomyces, Slackia, and Shuttleworthia; Table 1) were also predominant in adult wild JRP in various locations [52]. These bacterial genera are all anaerobic gut bacteria, except for Actinomyces. This latter genus comprises several species that can be isolated from soil [38]. Even though the possibility of inoculation from other sources (e.g., soil and food) does exist, the dominant bacterial OTUs are considered typical residents of the JRP gut and were likely derived from cecal feces of hens. The early onset of coprophagy in the chicks ( 3 to 4 days after hatching) toward the cecal feces of their hens facilitates the rapid establishment of "semi-adult"-type cecal microbiomes that include the common bacterial OTUs of adult JRPs.

The term "semi-adult"-type refers to the observation that the cecal microbiomes of the chicks were not complete during their first week. Indeed, the number of OTUs (Fig. 3) and alpha diversity (Fig. 4) of the cecal microbiome increased with host growth, and the proportion of several common OTUs changed with host growth (Table 1). Because most of the major OTUs were common to all stages, the observed increases in alpha diversity were mainly produced by quantitative changes in the microbiome (i.e., changes in the number of reads for each OTU). For example, Megasphaera sp., which was previously identified as one of the major OTUs of the adult JRP microbiome [52], was not abundant in the chick microbiomes (Table 1). Megasphaera sp. is an acidophilic gut bacterium that converts lactic acid to butyric acid [20], and it is likely that this bacterium can grow with other lactic acid producers. Therefore, the proliferation of Megasphaera sp. is likely facilitated by increases in lactic acid bacteria. The OTUs identified as Olsenella sp. and Bifidobacterium sp., which are recognized as potent lactate producers [2, 30], were also predominant in the adult gut microbiome and may support the proliferation of Megasphaera sp. This might explain the later development of Megasphaera sp. in the gut microbiomes of the chicks.

It is worth noting that coprophagy was not exhibited immediately after hatching but, rather, started at 3 or 4 days after hatching (Fig. 2). This lag time may reflect chicks' yolk sac retention. In chickens, the residual yolk sacs of chicks are absorbed over the 3 or 4 days following hatching [42] and supply the chicks with maternal immunoglobulins [53]. If the same process occurs in the JRP, chicks are protected by maternal immunoglobulin until 3 to 4 days after hatching. In mammals, maternal immunoglobulin, mainly IgA, is supplied by the mother's milk, and intestinal levels of IgA, in particular, are lowest during weaning, since maternal immunoglobulin is no longer supplied [54]. Interestingly, the alpha diversity of mammalian gut microbiomes starts to increase by weaning, when maternal immunoglobulin is exhausted [24-26]. If the same process occurs in the JRP, the time lag for the onset of coprophagy may reflect the time required to exhaust the residual yolk sac and, thus, maternal immunoglobulin.

The acquisition of the cecal microbiome through coprophagy during early growth stages seems to be adaptive for the JRP because precocial, herbivorous chicks must consume and digest the same food as their mothers (e.g., mature leaves and stems from alpine plants) by themselves shortly after hatching. This strategy has also been reported to occur in herbivorous mammals [4, 37] and reptiles [48, 57]. Because herbivores evolved independently in each lineage [46], this behavior can be defined as a convergent strategy among vertebrates that exhibit similar digestive strategies, to facilitate the transmission of essential gut bacteria across generations. In order to elucidate the role of allocoprophagy in the survival of JRP chicks, additional studies are needed to identify the bacterial OTUs at the strain level and to determine the functions of the strains as they are transmitted via coprophagy.

The results of the present study are valuable to ex-situ conservation programs associated with herbivorous hind-gut fermenters. 
Table 1. Common bacterial operational taxonomic units (OTUs) in the cecal microbiomes of Japanese rock ptarmigans at different ages

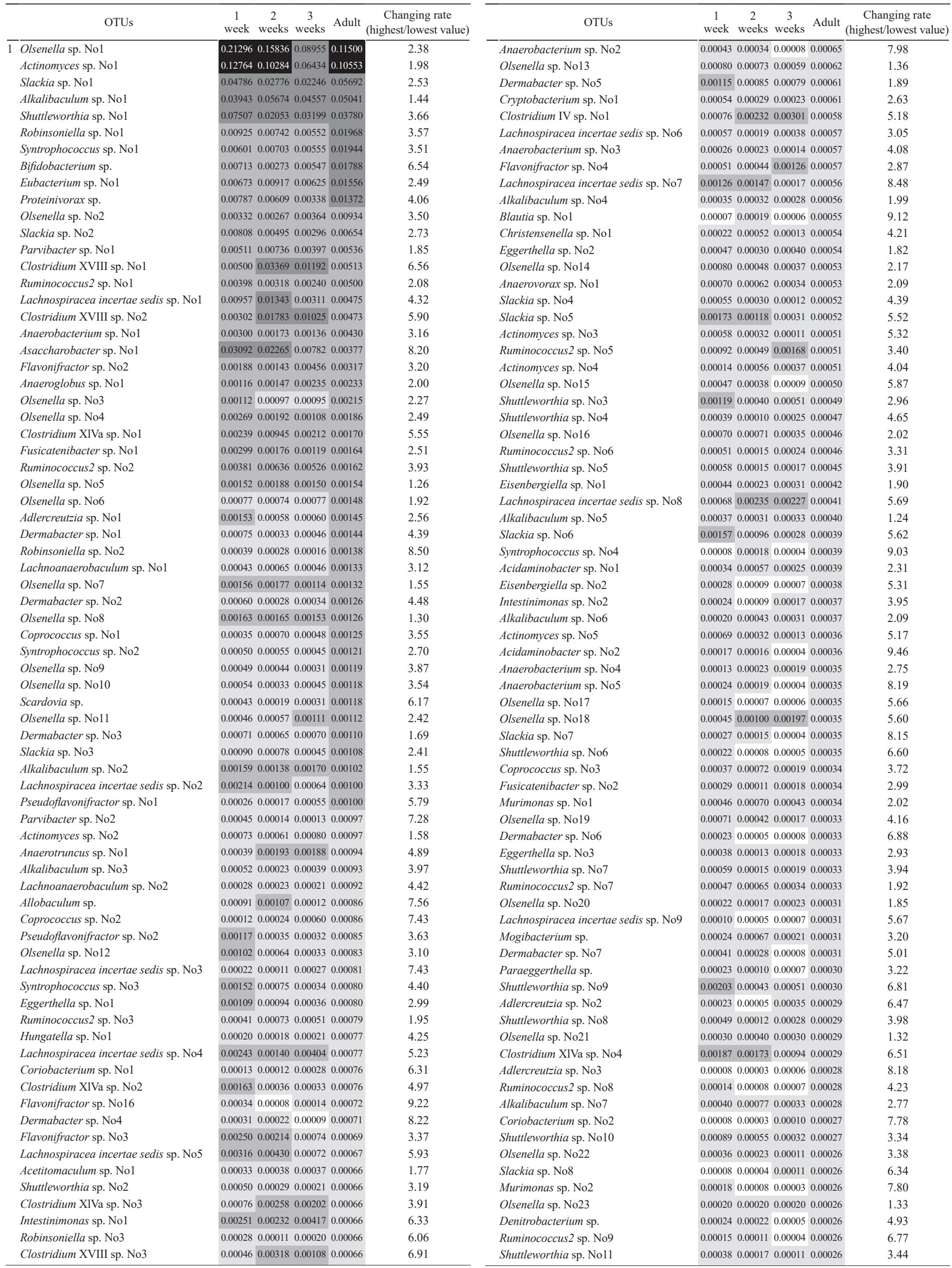




\begin{tabular}{|c|c|c|c|c|c|}
\hline OTUs & $\begin{array}{c}1 \\
\text { week }\end{array}$ & $\begin{array}{c}2 \\
\text { weeks }\end{array}$ & $\begin{array}{c}3 \\
\text { weeks }\end{array}$ & Adult & $\begin{array}{c}\text { Changing rate } \\
\text { (highest/lowest value) }\end{array}$ \\
\hline Clostridium XVIII sp. No4 & 0.00020 & 0.00073 & 0.00045 & 0.00025 & 3.71 \\
\hline Shuttleworthia sp. No12 & 0.00066 & 0.00017 & 0.00023 & 0.00025 & 3.93 \\
\hline Gordonibacter sp. & 0.00021 & 0.00016 & 0.00005 & 0.00024 & 4.64 \\
\hline Alkalibaculum sp. No8 & 0.00041 & 0.00013 & 0.00036 & 0.00024 & 3.21 \\
\hline Coprococcus sp. No4 & 0.00138 & 0.00085 & 0.00136 & 0.00024 & 5.86 \\
\hline Anaerobacterium sp. No6 & 0.00014 & 0.00005 & 0.00002 & 0.00023 & 9.76 \\
\hline Shuttleworthia sp. No13 & 0.00038 & 0.00015 & 0.00013 & 0.00023 & 2.87 \\
\hline Coprococcus sp. No5 & 0.00021 & 0.00017 & 0.00011 & 0.00022 & 1.86 \\
\hline Ruminococcus 2 sp. No10 & 0.00038 & 0.00011 & 0.00035 & 0.00022 & 3.53 \\
\hline Alkalibaculum sp. No9 & 0.00017 & 0.00003 & 0.00008 & 0.00022 & 8.02 \\
\hline Parvibacter sp. No3 & 0.00013 & 0.00009 & 0.00003 & 0.00022 & 6.58 \\
\hline Shuttleworthia sp. No14 & 0.00005 & 0.00020 & 0.00007 & 0.00021 & 4.47 \\
\hline Actinomyces sp. No6 & 0.00026 & 0.00042 & 0.00021 & 0.00020 & 2.05 \\
\hline Lachnospiracea incertae sedis sp. No10 & 0.00007 & 0.00005 & 0.00012 & 0.00020 & 3.61 \\
\hline Coprococcus sp. No6 & 0.00009 & 0.00005 & 0.00030 & 0.00020 & 5.44 \\
\hline Paraprevotella sp. & 0.00016 & 0.00004 & 0.00002 & 0.00020 & 8.18 \\
\hline Brassicibacter $\mathrm{sp}$. & 0.00012 & 0.00008 & 0.00003 & 0.00019 & 6.69 \\
\hline Lachnospiracea incertae sedis sp. No11 & 0.00078 & 0.00030 & 0.00013 & 0.00019 & 5.89 \\
\hline Clostridium XVIII sp. No5 & 0.00015 & 0.00043 & 0.00005 & 0.00019 & 8.92 \\
\hline Dermabacter sp. No8 & 0.00021 & 0.00013 & 0.00007 & 0.00019 & 2.99 \\
\hline Flavonifractor sp. No4 & 0.00005 & 0.00008 & 0.00049 & 0.00019 & 9.40 \\
\hline Catonella sp. & 0.00008 & 0.00003 & 0.00002 & 0.00019 & 7.75 \\
\hline Lachnospiracea incertae sedis sp. No12 & 0.00026 & 0.00014 & 0.00011 & 0.00018 & 2.47 \\
\hline Ruminococcus 2 sp. No11 & 0.00028 & 0.00014 & 0.00020 & 0.00018 & 2.08 \\
\hline Shuttleworthia sp. No15 & 0.00038 & 0.00016 & 0.00005 & 0.00018 & 7.15 \\
\hline Olsenella sp. No24 & 0.00052 & 0.00018 & 0.00017 & 0.00018 & 3.02 \\
\hline Fusicatenibacter sp. №3 & 0.00021 & 0.00010 & 0.00021 & 0.00018 & 2.12 \\
\hline Robinsoniella sp. No4 & 0.00007 & 0.00005 & 0.00013 & 0.00018 & 3.70 \\
\hline Olsenella sp. No25 & 0.00046 & 0.00031 & 0.00019 & 0.00017 & 1.50 \\
\hline Clostridium IV sp. No2 & 0.00010 & 0.00008 & 0.00008 & 0.00017 & 2.13 \\
\hline Murimonas sp. No3 & 0.00004 & 0.00018 & 0.00004 & 0.00017 & 4.47 \\
\hline Olsenella sp. No26 & 0.00039 & 0.00011 & 0.00019 & 0.00017 & 3.56 \\
\hline Shuttleworthia sp. No16 & 0.00033 & 0.00011 & 0.00007 & 0.00017 & 4.97 \\
\hline Lachnospiracea incertae sedis sp. No13 & 0.00007 & 0.00003 & 0.00007 & 0.00017 & 4.77 \\
\hline Dermabacter sp. No9 & 0.00015 & 0.00004 & 0.00017 & 0.00016 & 4.16 \\
\hline Hungatella sp. No2 & 0.00018 & 0.00009 & 0.00009 & 0.00016 & 1.66 \\
\hline Ruminococcus 2 sp. No12 & 0.00035 & 0.00040 & 0.00037 & 0.00015 & 2.73 \\
\hline Ruminococcus 2 sp. No13 & 0.00022 & 0.00015 & 0.00004 & 0.00015 & 5.77 \\
\hline Ruminococcus $2 \mathrm{sp.} \mathrm{No14}$ & 0.00009 & 0.00005 & 0.00009 & 0.00015 & 3.23 \\
\hline Anaerovorax sp. No2 & 0.00007 & 0.00029 & 0.00006 & 0.00015 & 4.99 \\
\hline Ruminococcus 2 sp. No15 & 0.00081 & 0.00009 & 0.00012 & 0.00015 & 8.57 \\
\hline Ethanoligenens sp. & 0.00004 & 0.00013 & 0.00008 & 0.00015 & 4.04 \\
\hline Shuttleworthia sp. No17 & 0.00030 & 0.00011 & 0.00012 & 0.00014 & 2.75 \\
\hline Alkalibaculum sp. No10 & 0.00025 & 0.00008 & 0.00008 & 0.00014 & 3.14 \\
\hline Lachnospiracea incertae sedis sp. No14 & 0.00062 & 0.00037 & 0.00020 & 0.00014 & 4.40 \\
\hline Clostridium XVIII sp. No6 & 0.00010 & 0.00041 & 0.00040 & 0.00014 & 4.00 \\
\hline Robinsoniella sp. No5 & 0.00026 & 0.00025 & 0.00026 & 0.00014 & 1.90 \\
\hline Christensenella sp. №2 & 0.00011 & 0.00079 & 0.00074 & 0.00014 & 7.33 \\
\hline Eubacterium sp. No2 & 0.00004 & 0.00007 & 0.00002 & 0.00013 & 7.01 \\
\hline Lachnospiracea incertae sedis sp. No15 & 0.00003 & 0.00010 & 0.00015 & 0.00013 & 5.71 \\
\hline Flavonifractor sp. No5 & 0.00006 & 0.00029 & 0.00025 & 0.00013 & 5.17 \\
\hline Lachnospiracea incertae sedis sp. No16 & 0.00009 & 0.00005 & 0.00012 & 0.00013 & 2.79 \\
\hline Acetanaerobacterium sp. & 0.00006 & 0.00030 & 0.00013 & 0.00013 & 5.29 \\
\hline Shuttleworthia sp. No18 & 0.00041 & 0.00059 & 0.00020 & 0.00013 & 4.63 \\
\hline Intestinimonas sp. No3 & 0.00002 & 0.00021 & 0.00020 & 0.00012 & 9.46 \\
\hline Olsenella sp. No27 & 0.00003 & 0.00005 & 0.00015 & 0.00012 & 4.74 \\
\hline Papillibacter sp. No1 & 0.00023 & 0.00035 & 0.00048 & 0.00012 & 4.03 \\
\hline Olsenella sp. No29 & 0.00023 & 0.00021 & 0.00012 & 0.00012 & 1.90 \\
\hline Olsenella sp. No28 & 0.00023 & 0.00045 & 0.00026 & 0.00012 & 3.76 \\
\hline Robinsoniella sp. No6 & 0.00030 & 0.00020 & 0.00006 & 0.00012 & 4.61 \\
\hline Shuttleworthia sp. No19 & 0.00021 & 0.00005 & 0.00008 & 0.00012 & 3.82 \\
\hline Slackia sp. No9 & 0.00008 & 0.00007 & 0.00003 & 0.00011 & 3.42 \\
\hline Slackia sp. No10 & 0.00011 & 0.00003 & 0.00006 & 0.00011 & 4.07 \\
\hline Olsenella sp. No30 & 0.00045 & 0.00020 & 0.00005 & 0.00011 & 8.55 \\
\hline Dermabacter sp. No10 & 0.00014 & 0.00009 & 0.00003 & 0.00011 & 4.05 \\
\hline Desulfitispora sp. & 0.00014 & 0.00016 & 0.00007 & 0.00011 & 2.45 \\
\hline Ruminococcus 2 sp. No16 & 0.00014 & 0.00023 & 0.00012 & 0.00011 & 2.14 \\
\hline Dermabacter sp. No11 & 0.00021 & 0.00018 & 0.00009 & 0.00011 & 2.23 \\
\hline Flavonifractor sp. No6 & 0.00011 & 0.00020 & 0.00039 & 0.00011 & 3.70 \\
\hline Clostridium XVIII sp. No7 & 0.00004 & 0.00024 & 0.00014 & 0.00011 & 6.10 \\
\hline Ruminococcus 2 sp. No17 & 0.00006 & 0.00004 & 0.00007 & 0.00011 & 2.68 \\
\hline Pseudoflavonifractor $\mathrm{sp}$. No3 & 0.00007 & 0.00012 & 0.00009 & 0.00010 & 1.54 \\
\hline Anaerotruncus sp. No2 & 0.00004 & 0.00007 & 0.00008 & 0.00010 & 2.42 \\
\hline Ruminococcus 2 sp. No18 & 0.00073 & 0.00009 & 0.00010 & 0.00010 & 8.29 \\
\hline Shuttleworthia sp. No20 & 0.00044 & 0.00020 & 0.00010 & 0.00010 & 4.42 \\
\hline
\end{tabular}

\begin{tabular}{l} 
OTUs \\
\hline Hungatella sp. No3 \\
Fusicatenibacter sp. No4 \\
Olsenella sp. No31 \\
Flavonifractor sp. No7 \\
Ruminococcus sp. \\
Clostridium XVIII sp. No8 \\
Clostridium XVIII sp. No9 \\
Olsenella sp. No32 \\
Olsenella sp. No33 \\
Olsenella sp. No34 \\
Parvibacter sp. No4 \\
Flavonifractor sp. No8 \\
Eisenbergiella sp. No3 \\
Anaerosolibacter sp. \\
Robinsoniella sp. No7 \\
Lachnospiracea incertae sedis sp. No17 \\
Lachnospiracea incertae sedis sp. No18 \\
Pseudoflavonifractor sp. No4 \\
Shuttleworthia sp. No21 \\
Adlercreutzia sp. No4 \\
Clostridium XVIII sp. No10
\end{tabular}

Lachnospiracea incertae sedis sp. No19 Dermabacter sp. No12

Acetitomaculum sp. No2

Ruminococcus 2 sp. No35

Coprococcus sp. No8

Coprococcus sp. No7

Ruminococcus 2 sp. No19

Olsenella sp. No35

Shuttleworthia sp. No22

Clostridium XIVa sp. No5

Olsenella sp. No36

Ruminococcus 2 sp. No20

Parvibacter sp. No5

Ruminococcus2 sp. No21

Olsenella sp. No37

Ruminococcus 2 sp. No22

Coprococcus sp. No9

Lachnospiracea incertae sedis sp. No20 Clostridium XIVa sp. No6

Marvinbryantia sp.

Clostridium XVIII sp. No11

Parvibacter sp. No6

Olsenella sp. No38

Ruminococcus2 sp. No23

Olsenella sp. No39

Pseudoflavonifractor sp. No5

Robinsoniella sp. No8

Lachnospiracea incertae sedis sp. No21

Christensenella sp. No3

Arthrobacter sp.

Cryptobacterium sp. No2

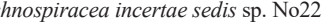

Ruminococcus $2 \mathrm{sp}$. No24

Coprococcus sp. No10 0.000060 .000080 .000020 .0000

us $\mathrm{sp}$. No10

Hungatella sp. No4

Dialister sp.

Megamonas sp. Nol

Coprococcus sp. No11

Hungatella sp. No5

Sporobacter sp. No

Lachnospiracea incertae sedis sp. No27

Megamonas sp. No2

Murimonas sp. No4

Dermabacter sp. No14

3 Ruminococcus 2 sp. № $26---\cdots$

Olsenella sp. No40

Olsenella sp. No41

Ruminococcus 2 sp. No28

Ruminococcus $2 \mathrm{sp}$. No29

Ruminococcus $2 \mathrm{sp}$. No27

Ruminococcus 2 sp. No3 $\begin{array}{ccc}1 & 2 & 3 \\ \text { week } & \text { weeks } & \text { weeks }\end{array}$ Adult $\begin{gathered}\text { Changing rate } \\ \text { (highest/lowest }\end{gathered}$

$0.000090 .000030 .00009 \quad 3.31$

$\begin{array}{lllll}0.00006 & 0.00023 & 0.00053 & 0.00009 & 8.31\end{array}$

$\begin{array}{llll}0.00004 & 0.00003 & 0.00009 & 6.51\end{array}$

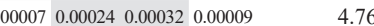

$\begin{array}{llllll}0.00002 & 0.00011 & 0.00009 & 0.00009 & 5.20\end{array}$

$\begin{array}{llll}0.0000 & 0.0009 & 0.0009 & 7.39\end{array}$

$\begin{array}{llllll}0.00007 & 0.00018 & 0.00003 & 0.00008 & 5.56\end{array}$

$0.00017 \quad 0.00030 \quad 0.00008$

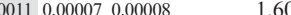

$\begin{array}{lllll}0.00020 & 0.00014 & 0.00033 & 0.00008 & 4.37\end{array}$

$\begin{array}{llll}0.00015 & 0.00008 & 0.00007 & 3.74\end{array}$

$\begin{array}{lllllll}0.00000 & 0.00039 & 0.00007 & 5.31\end{array}$

2.00

$\begin{array}{lllll}0.00004 & 0.00003 & 0.00007 & 0.00007 & 2.25\end{array}$

$\begin{array}{lllll}0.0030 & 0.00026 & 0.00045 & 0.00006 & 7.17\end{array}$

$160.000270 .00006 \quad 7.40$

0.000030 .000080 .00006

$\begin{array}{lllll}0.00022 & 0.00003 & 0.00006 & 8.76\end{array}$

8.83

3.90

8.49

9.45

2.96

6.45

3.96

2.82

5.50

6.05

4.09

9.70

4.85

4.51

3.77

6.96

4.75

8.02

6.53

8.96

2.98

8.02

6.99

2.67

6.18

3.66

8.62

4.17

2.23

7.40

6.54

3.17

7.21

6.00

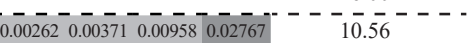

$\begin{array}{lllll}0.00048 & 0.00100 & 0.00269 & 0.00860\end{array}$

$\begin{array}{llllll}0.00020 & 0.00013 & 0.00027 & 0.00395\end{array}$

17.98

30.95

19.34 $\begin{array}{lllll}0.00001 & 0.00014 & 0.00002 & 0.00067 & 88.05\end{array}$

$\begin{array}{llllll}0.00002 & 0.00007 & 0.00011 & 0.00033 & 15.47\end{array}$

$\begin{array}{lllll}0.00002 & 0.00009 & 0.00016 & 0.00018 & 10.40\end{array}$

22.04

16.06

10.81

15.11 $\begin{array}{lllllll}0.00001 & 0.00003 & 0.00003 & 0.00014\end{array}$

$\begin{array}{lllll}0.0001 & 0.00003 & 0.00011 & 0.00009\end{array}$

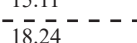

0.004090 .002510 .000660 .0034

12.06

12.49

16.72

14.44

44.10

19.07 


\begin{tabular}{|c|c|c|c|c|c|}
\hline OTUs & $\begin{array}{c}1 \\
\text { week }\end{array}$ & $\begin{array}{c}2 \\
\text { weeks }\end{array}$ & $\begin{array}{c}3 \\
\text { weeks }\end{array}$ & Adult & $\begin{array}{c}\text { Changing rate } \\
\text { (highest/lowest value) }\end{array}$ \\
\hline Ruminococcus 2 sp. No30 & 0.00204 & 0.00067 & 0.00042 & 0.00007 & 28.12 \\
\hline Dermabacter sp. No13 & 0.00076 & 0.00034 & 0.00020 & 0.00007 & 10.55 \\
\hline Olsenella sp. No45 & 0.00089 & 0.00053 & 0.00015 & 0.00007 & 13.33 \\
\hline Shuttleworthia sp. No23 & 0.00136 & 0.00118 & 0.00032 & 0.00007 & 20.37 \\
\hline Lachnospiracea incertae sedis sp. №24 & 0.00109 & 0.00012 & 0.00020 & 0.00005 & 21.37 \\
\hline Olsenella sp. No42 & 0.00098 & 0.00044 & 0.00016 & 0.00005 & 19.90 \\
\hline Olsenella sp. No43 & 0.00093 & 0.00054 & 0.00012 & 0.00005 & 19.00 \\
\hline Ruminococcus 2 sp. No32 & 0.00110 & 0.00006 & 0.00006 & 0.00005 & 22.90 \\
\hline Olsenella sp. No44 & 0.00092 & 0.00044 & 0.00025 & 0.00005 & 20.06 \\
\hline Parvibacter sp. No7 & 0.00051 & 0.00042 & 0.00012 & 0.00005 & 11.17 \\
\hline Olsenella sp. No46 & 0.00065 & 0.00042 & 0.00005 & 0.00003 & 18.62 \\
\hline Ruminococcus 2 sp. No34 & 0.00080 & 0.00110 & 0.00112 & 0.00003 & 33.17 \\
\hline Ruminococcus 2 sp. No37 & 0.00034 & 0.00022 & 0.00004 & 0.00003 & 10.22 \\
\hline Lachnospiracea incertae sedis sp. №25 & 0.00036 & 0.00013 & 0.00009 & 0.00003 & 11.75 \\
\hline Shuttleworthia sp. No24 & 0.00069 & 0.00014 & 0.00010 & 0.00003 & 23.90 \\
\hline Lachnospiracea incertae sedis sp. №26 & 0.00032 & 0.00030 & 0.00009 & 0.00003 & 12.00 \\
\hline Slackia sp. No11 & 0.00047 & 0.00022 & 0.00002 & 0.00003 & 18.51 \\
\hline Ruminococcus 2 sp. No38 & 0.00024 & 0.00012 & 0.00022 & 0.00002 & 13.52 \\
\hline Asaccharobacter sp. No2 & 0.00034 & 0.00026 & 0.00010 & 0.00002 & 18.63 \\
\hline Parvibacter sp. No8 & 0.00038 & 0.00007 & 0.00007 & 0.00002 & 21.36 \\
\hline Ruminococcus2 sp. No33 & 0.00091 & 0.00006 & 0.00034 & 0.00001 & 63.07 \\
\hline Lachnospira sp. & 0.00060 & 0.00013 & 0.00026 & 0.00001 & 41.63 \\
\hline Cryptobacterium sp. No3 & 0.00023 & 0.00035 & 0.00017 & 0.00001 & 24.03 \\
\hline Ruminococcus 2 sp. No36 & 0.00038 & 0.00003 & 0.00015 & 0.00001 & 26.13 \\
\hline Adlercreutzia sp. No5 & 0.00048 & 0.00003 & 0.00003 & 0.00001 & 36.24 \\
\hline $4 \overline{\text { Megasphaera sp. }}$. & $0 . \overline{0}-\overline{-} \overline{75}$ & 0.00064 & $\overline{0.00}$ & $0 . \overline{05158}$ & $\overline{80 . \overline{59}}$ \\
\hline Erysipelotrichaceae_incertae_sedis sp. No1 & 0.00240 & 0.12181 & 0.03535 & 0.04108 & 50.76 \\
\hline Defluviitalea sp. No1 & 0.00278 & 0.00433 & 0.00041 & 0.02061 & 50.75 \\
\hline Megamonas sp. No3 & 0.00177 & 0.00453 & 0.03218 & 0.01952 & 18.19 \\
\hline Fusicatenibacter sp. No6 & 0.00269 & 0.00293 & 0.00060 & 0.01662 & 27.61 \\
\hline Alkalibaculum sp. No12 & 0.00326 & 0.00107 & 0.00036 & 0.01509 & 41.56 \\
\hline Citrobacter $\mathrm{sp}$. & 0.00005 & 0.00008 & 0.03688 & 0.01270 & 744.21 \\
\hline Flavonifractor sp. No1 & 0.00294 & 0.01398 & 0.02995 & 0.00518 & 10.20 \\
\hline Faecalitalea sp. & 0.00132 & 0.00075 & 0.00024 & 0.00351 & 14.40 \\
\hline Anaeroglobus sp. No2 & 0.00022 & 0.00005 & 0.00057 & 0.00347 & 63.16 \\
\hline Alkalibaculum sp. No14 & 0.00090 & 0.00033 & 0.00017 & 0.00259 & 15.56 \\
\hline Anaerorhabdus sp. & 0.00070 & 0.00058 & 0.00022 & 0.00238 & 10.67 \\
\hline Papillibacter sp. No2 & 0.00046 & 0.00020 & 0.00034 & 0.00201 & 10.01 \\
\hline Hungatella sp. No6 & 0.00018 & 0.00009 & 0.00005 & 0.00199 & 37.84 \\
\hline Anaerobacterium sp. No7 & 0.00127 & 0.00079 & 0.00002 & 0.00198 & 82.79 \\
\hline Alkalibaculum sp. No13 & 0.00042 & 0.00007 & 0.00005 & 0.00186 & 35.45 \\
\hline Defluviitalea sp. No2 & 0.00011 & 0.00010 & 0.00003 & 0.00162 & 56.62 \\
\hline Anaerospora sp. & 0.00009 & 0.00045 & 0.00470 & 0.00135 & 54.11 \\
\hline Anaerobacterium sp. No10 & 0.00009 & 0.00017 & 0.00003 & 0.00135 & 40.36 \\
\hline Sporobacter sp. No2 & 0.00054 & 0.00005 & 0.00029 & 0.00132 & 23.94 \\
\hline Acetatifactor sp. & 0.00015 & 0.00004 & 0.00046 & 0.00125 & 34.41 \\
\hline Robinsoniella sp. No9 & 0.00010 & 0.00015 & 0.00005 & 0.00111 & 23.23 \\
\hline Pseudoflavonifractor $\mathrm{sp}$. No8 & 0.00031 & 0.00006 & 0.00006 & 0.00105 & 16.69 \\
\hline Parvibacter sp. No11 & 0.00033 & 0.00026 & 0.00009 & 0.00097 & 10.64 \\
\hline Clostridium XIVa sp. No10 & 0.00015 & 0.00148 & 0.00225 & 0.00085 & 14.56 \\
\hline Slackia sp. No13 & 0.00020 & 0.00006 & 0.00023 & 0.00079 & 13.30 \\
\hline Lachnospiracea incertae sedis sp. №32 & 0.00019 & 0.00005 & 0.00038 & 0.00077 & 16.84 \\
\hline Megamonas sp. No5 & 0.00009 & 0.00003 & 0.00029 & 0.00075 & 23.86 \\
\hline Clostridium XIVa sp. No11 & 0.00017 & 0.00043 & 0.00002 & 0.00074 & 38.74 \\
\hline Anaerobacterium sp. No8 & 0.00019 & 0.00005 & 0.00004 & 0.00071 & 16.62 \\
\hline Psychrosinus sp. No1 & 0.00014 & 0.00004 & 0.00007 & 0.00068 & 18.75 \\
\hline Acidaminobacter sp. No3 & 0.00005 & 0.00008 & 0.00002 & 0.00064 & 33.38 \\
\hline Geosporobacter sp. No2 & 0.00005 & 0.00006 & 0.00002 & 0.00063 & 33.07 \\
\hline Coprococcus sp. No16 & 0.00045 & 0.01062 & 0.00195 & 0.00063 & 23.78 \\
\hline Anaerobacterium sp. No9 & 0.00015 & 0.00023 & 0.00003 & 0.00062 & 21.48 \\
\hline Flavonifractor sp. No9 & 0.00025 & 0.00152 & 0.00405 & 0.00059 & 16.21 \\
\hline Ruminococcus 2 sp. No4 & 0.00200 & 0.00223 & 0.00596 & 0.00059 & 10.15 \\
\hline Psychrosinus sp. No2 & 0.00004 & 0.00006 & 0.00002 & 0.00056 & 29.50 \\
\hline Geosporobacter sp. No1 & 0.00011 & 0.00014 & 0.00004 & 0.00055 & 12.85 \\
\hline Dermabacter sp. No16 & 0.00004 & 0.00010 & 0.00004 & 0.00055 & 14.38 \\
\hline Parvibacter sp. No9 & 0.00026 & 0.00278 & 0.00171 & 0.00050 & 10.65 \\
\hline Anaerobacterium sp. No11 & 0.00007 & 0.00006 & 0.00005 & 0.00049 & 10.32 \\
\hline Slackia sp. No14 & 0.00008 & 0.00003 & 0.00013 & 0.00049 & 14.04 \\
\hline Eisenbergiella sp. No4 & 0.00025 & 0.00028 & 0.00002 & 0.00047 & 24.59 \\
\hline
\end{tabular}

\begin{tabular}{|c|c|c|c|c|c|}
\hline OTUs & $\begin{array}{c}1 \\
\text { week }\end{array}$ & $\begin{array}{c}2 \\
\text { weeks }\end{array}$ & $\begin{array}{c}3 \\
\text { weeks }\end{array}$ & Adult & $\begin{array}{c}\text { Changing rate } \\
\text { (highest/lowest value) }\end{array}$ \\
\hline Olsenella sp. No48 & 0.00128 & 0.00009 & 0.00022 & 20.00047 & 14.83 \\
\hline Adlercreutzia sp. No6 & 0.00045 & 0.00003 & 0.00015 & 0.00045 & 14.34 \\
\hline Olsenella sp. No50 & 0.00009 & 0.00003 & 0.00006 & 60.00038 & 13.65 \\
\hline Anaerotruncus sp. No3 & 0.00010 & 0.00008 & 0.00002 & 20.00034 & 14.31 \\
\hline Ruminococcus 2 sp. No47 & 0.00223 & 0.00016 & 0.00035 & 0.00033 & 14.31 \\
\hline Coprococcus sp. No12 & 0.00080 & 0.00146 & 0.00618 & 0.00033 & 18.84 \\
\hline Olsenella sp. No51 & 0.00012 & 0.00028 & 0.00003 & 0.00032 & 11.04 \\
\hline Syntrophococcus sp. No5 & 0.00012 & 0.00017 & 0.00002 & 20.00028 & 14.40 \\
\hline Coprococcus sp. No20 & 0.00003 & 0.00075 & 0.00115 & 0.00027 & 45.06 \\
\hline Clostridium XIVa sp. No9 & 0.00026 & 0.01079 & 0.00213 & 0.00026 & 40.95 \\
\hline Faecalicoccus sp. & 0.00029 & 0.00226 & 0.00573 & 0.00023 & 24.79 \\
\hline Alkalibaculum sp. No11 & 0.00002 & 0.00076 & 0.00038 & 0.00022 & 31.32 \\
\hline Anaerobacterium sp. No12 & 0.00026 & 0.00014 & 0.00002 & 20.00022 & 10.83 \\
\hline Ruminococcus 2 sp. No43 & 0.00020 & 0.00541 & 0.01766 & 0.00021 & 88.56 \\
\hline Pseudoflavonifractor sp. No6 & 0.00058 & 0.00130 & 0.00261 & 0.00019 & 13.42 \\
\hline Dorea $\mathrm{sp}$. & 0.00226 & 0.00599 & 0.00546 & 60.00019 & 31.21 \\
\hline Ruminococcus2 sp. No39 & 0.00142 & 0.00216 & 0.00164 & 40.00018 & 12.33 \\
\hline Anaerovorax sp. No4 & 0.00002 & 0.00061 & 0.00006 & 60.00017 & 24.61 \\
\hline Erysipelotrichaceae_incertae_sedis sp. No3 & 0.00001 & 0.00039 & 0.00034 & 40.00015 & 40.79 \\
\hline 5 Slackia sp. $-\overline{\mathrm{No}} 12$ & $0 . \overline{0} \overline{123}$ & 0.00079 & -0.0000 & $\overline{8} 0 . \overline{0} 0014$ & $-\overline{5} . \overline{10}$ \\
\hline Lactococcus sp. No1 & 0.00008 & 0.00131 & 0.00080 & 0.00014 & 15.58 \\
\hline Erysipelotrichaceae_incertae_sedis sp. No4 & 0.00001 & 0.00023 & 0.00005 & 50.00013 & 31.01 \\
\hline Ruminococcus 2 sp. No41 & 0.00051 & 0.00225 & 0.01613 & 0.00011 & 152.57 \\
\hline Flavonifractor $\mathrm{sp}$. No12 & 0.00002 & 0.00022 & 0.00061 & 10.00010 & 40.00 \\
\hline Erysipelotrichaceae_incertae_sedis sp. No2 & 0.00001 & 0.00025 & 0.00019 & 0.00009 & 17.28 \\
\hline Fusicatenibacter sp. No5 & 0.00013 & 0.00111 & 0.00119 & 0.00009 & 12.83 \\
\hline Flavonifractor sp. No15 & 0.00003 & 0.00017 & 0.00062 & 20.00009 & 21.49 \\
\hline Clostridium XVIII sp. No12 & 0.00003 & 0.00044 & 0.00018 & 0.00009 & 15.39 \\
\hline Anaerovorax sp. No3 & 0.00006 & 0.00020 & 0.00002 & 20.00009 & 10.30 \\
\hline Megamonas sp. No4 & 0.00001 & 0.00004 & 0.00017 & 70.00009 & 23.99 \\
\hline Clostridium XIVa sp. No8 & 0.00057 & 0.00331 & 0.00208 & 0.00008 & 40.86 \\
\hline Flavonifractor $\mathrm{sp}$. No10 & 0.00004 & 0.00028 & 0.00057 & 70.00008 & 13.60 \\
\hline Clostridium XIVa sp. No7 & 0.00155 & 0.00529 & 0.00406 & 60.00008 & 67.86 \\
\hline Ruminococcus 2 sp. No48 & 0.00100 & 0.00007 & 0.00035 & 0.00008 & 14.15 \\
\hline Coprococcus sp. No13 & 0.00003 & 0.00124 & 0.00014 & 40.00007 & 37.56 \\
\hline Coprococcus sp. No14 & 0.00058 & 0.00282 & 0.00108 & 30.00006 & 46.00 \\
\hline Olsenella sp. No52 & 0.00073 & 0.00037 & 0.00005 & 50.00006 & 15.18 \\
\hline Blautia sp. No3 & 0.00009 & 0.00058 & 0.00096 & 0.00006 & 16.07 \\
\hline Flavonifractor sp. No11 & 0.00002 & 0.00010 & 0.00054 & 40.00006 & 24.72 \\
\hline Lachnospiracea incertae sedis sp. №31 & 0.00091 & 0.00016 & 0.00005 & 50.00006 & 19.11 \\
\hline Ruminococcus 2 sp. No42 & 0.00032 & 0.00043 & 0.00066 & 6.00006 & 11.71 \\
\hline Eubacterium sp. No3 & 0.00001 & 0.00013 & 0.00028 & 0.00005 & 23.43 \\
\hline Olsenella sp. No49 & 0.00046 & 0.00023 & 0.00002 & 20.00005 & 24.22 \\
\hline Ruminococcus2 sp. No46 & 0.00004 & 0.00026 & 0.00085 & 0.00005 & 24.08 \\
\hline Flavonifractor $\mathrm{sp}$. No13 & 0.00001 & 0.00022 & 0.00075 & 50.00005 & 60.39 \\
\hline Olsenella sp. No47 & 0.00008 & 0.00021 & 0.00049 & 0.00005 & 10.69 \\
\hline Dermabacter sp. No15 & 0.00001 & 0.00019 & 0.00004 & 40.00005 & 19.64 \\
\hline Lachnospiracea incertae sedis sp. №30 & 0.00006 & 0.00343 & 0.00296 & 0.00005 & 75.56 \\
\hline Ruminococcus 2 sp. No49 & 0.00044 & 0.00003 & 0.00017 & 70.00004 & 16.07 \\
\hline Blautia sp. No2 & 0.00019 & 0.00643 & 0.00396 & 0.00003 & 194.58 \\
\hline Pseudoflavonifractor sp. No7 & 0.00001 & 0.00008 & 0.00039 & 0.00003 & 41.34 \\
\hline Parvibacter sp. No10 & 0.00006 & 0.00038 & 0.00003 & 30.00003 & 11.52 \\
\hline Lachnospiracea incertae sedis sp. №29 & 0.00025 & 0.00188 & 0.01029 & 0.00003 & 357.50 \\
\hline Coprococcus sp. No15 & 0.00049 & 0.00229 & 0.00080 & 0.00003 & 79.59 \\
\hline Ruminococcus 2 sp. No45 & 0.00005 & 0.00037 & 0.00316 & 6.00003 & 119.36 \\
\hline Lachnospiracea incertae sedis sp. №28 & 0.00030 & 0.00014 & 0.00070 & 0.00003 & 26.53 \\
\hline Coprococcus sp. No19 & 0.00001 & 0.00013 & 0.00016 & 50.00003 & 21.07 \\
\hline Butyricicoccus sp. & 0.00022 & 0.00019 & 0.00055 & 50.00003 & 21.82 \\
\hline Shuttleworthia sp. №25 & 0.00008 & 0.00012 & 0.00042 & 20.00003 & 16.71 \\
\hline Intestinimonas sp. No4 & 0.00013 & 0.00026 & 0.00035 & 50.00002 & 16.36 \\
\hline Coprococcus sp. No17 & 0.00033 & 0.00051 & 0.00010 & 0.00002 & 25.55 \\
\hline Coprococcus sp. No18 & 0.00013 & 0.00005 & 0.00044 & 40.00002 & 24.32 \\
\hline Lactococcus sp. No2 & 0.00001 & 0.00023 & 0.00030 & 0.00002 & 22.82 \\
\hline Ruminococcus 2 sp. No44 & 0.00007 & 0.00017 & 0.00038 & 0.00002 & 22.88 \\
\hline Ruminococcus 2 sp. No40 & 0.00065 & 0.00456 & 0.04151 & 0.00001 & 2884.43 \\
\hline Flavonifractor sp. No14 & 0.00001 & 0.00004 & 0.00018 & 0.00001 & 12.83 \\
\hline Ruminococcus2 sp. №25 & 0.00002 & 0.00015 & 0.00009 & 0.00001 & 10.31 \\
\hline Total & 0.93046 & 0.91477 & 0.79141 & 10.88821 & \\
\hline
\end{tabular}


Some studies have reported significant differences between the gut microbiomes of wild and captive individuals and that such differences are the result of diet and feed additives, such as antimicrobials $[3,51,55,65]$. Understanding such captivity-related modifications to the gut microbiome is critical for conserving endangered species [64], considering that the loss or perturbation of a functional gut microbiome could be fatal to captive herbivores, when they need to consume wild plants that are rich in toxic and anti-herbivore chemicals [15]. The reconstruction of wild-type gut microbiomes prior to the reintroduction of captive animals may be essential to improve the results of JRP re-introduction programs. The results of the present study indicate that inoculation with fresh fecal microbes from healthy wild individuals at early life stages is one method by which to reconstruct the wild-type gut microbiome.

ACKNOWLEDGMENTS. This work was financially supported by the Environment Research and Technology Development Fund (ERTDF 4-1604 and 4-1903). The kind support of the Kitadake Sanso Lodge is acknowledged. We are grateful to anonymous reviewers for their valuable comments on our manuscript.

\section{REFERENCES}

1. Ballou, A. L., Ali, R. A., Mendoza, M. A., Ellis, J. C., Hassan, H. M., Croom, W. J. and Koci, M. D. 2016. Development of the chick microbiome: how early exposure influences future microbial diversity. Front. Vet. Sci. 3: 2. [Medline] [CrossRef]

2. Bezkorovainy, A. and Miller-Catchpole, R. 1989. Biochemistry and Physiology of Bifidobacteria. CRC Press, Boca Raton.

3. Borbón-García, A., Reyes, A., Vives-Flórez, M. and Caballero, S. 2017. Captivity shapes the gut microbiota of Andean bears: insights into health surveillance. Front. Microbiol. 8: 1316. [Medline] [CrossRef]

4. Crowell-Davis, S. L. and Houpt, K. A. 1985. Coprophagy by foals: effect of age and possible functions. Equine Vet. J. 17: 17-19. [Medline] [CrossRef]

5. Danzeisen, J. L., Calvert, A. J., Noll, S. L., McComb, B., Sherwood, J. S., Logue, C. M. and Johnson, T. J. 2013. Succession of the turkey gastrointestinal bacterial microbiome related to weight gain. PeerJ 1: e237. [Medline] [CrossRef]

6. Ding, J., Dai, R., Yang, L., He, C., Xu, K., Liu, S., Zhao, W., Xiao, L., Luo, L., Zhang, Y. and Meng, H. 2017. Inheritance and establishment of gut microbiota in chickens. Front. Microbiol. 8: 1967. [Medline] [CrossRef]

7. Donaldson, E. E., Stanley, D., Hughes, R. J. and Moore, R. J. 2017. The time-course of broiler intestinal microbiota development after administration of cecal contents to incubating eggs. PeerJ 5: e3587. [Medline] [CrossRef]

8. Dudley, R. and Vermeij, G. J. 1992. Do the power requirements of flapping flight constrain folivory in flying animals? Funct. Ecol. 6: 101-104.

9. Edgar, R. C. 2010. Search and clustering orders of magnitude faster than BLAST. Bioinformatics 26: 2460-2461. [Medline] [CrossRef]

10. Edgar, R. C., Haas, B. J., Clemente, J. C., Quince, C. and Knight, R. 2011. UCHIME improves sensitivity and speed of chimera detection. Bioinformatics 27: 2194-2200. [Medline] [CrossRef]

11. Engel, P. and Moran, N. A. 2013. The gut microbiota of insects - diversity in structure and function. FEMS Microbiol. Rev. 37: 699-735. [Medline] [CrossRef]

12. Environmental ministry Japan. 2012. Program for the Rehabilitation of Natural Habitats and Maintenance of Viable Population, Environmental ministry Japan, Tokyo.

13. Ezenwa, V. O., Gerardo, N. M., Inouye, D. W., Medina, M. and Xavier, J. B. 2012. Microbiology. Animal behavior and the microbiome. Science 338: 198-199. [Medline] [CrossRef]

14. Frankenberg, D. and Smith, K. L. Jr. 1967. Coprophagy in marine animals 1. Limnol. Oceanogr. 12: 443-450. [CrossRef]

15. Forbey, J. S., Liu, R., Caughlin, T. T., Matocq, M. D., Vucetich, J. A., Kohl, K. D., Dearing, M. D. and Felton, A. M. 2018. Review: Using physiologically based models to predict population responses to phytochemicals by wild vertebrate herbivores. Animal 12 s2: s383-s398. [Medline] [CrossRef]

16. Gill, F. and Donsker, D. 2018. IOC World Bird List (v5.1). Available online at: http://www.worldbirdnames.org/ [Accessed November 24, 2018].

17. Grajal, A. 1995. Structure and function of the digestive tract of the hoatzin (Opisthocomus hoazin): a folivorous bird with foregut fermentation. Auk 112: 20-28. [CrossRef]

18. Grond, K., Lanctot, R. B., Jumpponen, A. and Sandercock, B. K. 2017. Recruitment and establishment of the gut microbiome in arctic shorebirds. FEMS Microbiol. Ecol. 93: fix142. [Medline] [CrossRef]

19. Grond, K., Sandercock, B. K., Jumpponen, A. and Zeglin, L. H. 2018. The avian gut microbiota: community, physiology and function in wild birds. J. Avian Biol. 49: e01788. [CrossRef]

20. Hashizume, K., Tsukahara, T., Yamada, K., Koyama, H. and Ushida, K. 2003. Megasphaera elsdenii JCM1772T normalizes hyperlactate production in the large intestine of fructooligosaccharide-fed rats by stimulating butyrate production. J. Nutr. 133: 3187-3190. [Medline] [CrossRef]

21. Hayaishi, S. and Kawamoto, Y. 2006. Low genetic diversity and biased distribution of mitochondrial DNA haplotypes in the Japanese macaque (Macaca fuscata yakui) on Yakushima Island. Primates 47: 158-164. [Medline] [CrossRef]

22. Hirakawa, H. 2001. Coprophagy in leporids and other mammalian herbivores. Mammol. Rev. 31: 61-80. [CrossRef]

23. Hurd, P. L., Weatherhead, P. J. and McRae, S. B. 1991. Parental consumption of nestling feces: good food or sound economics? Behav. Ecol. 2: 69-76. [CrossRef]

24. Inoue, R. and Ushida, K. 2003. Development of the intestinal microbiota in rats and its possible interactions with the evolution of the luminal IgA in the intestine. FEMS Microbiol. Ecol. 45: 147-153. [Medline] [CrossRef]

25. Inoue, R., Otsuka, M. and Ushida, K. 2005. Development of intestinal microbiota in mice and its possible interaction with the evolution of luminal IgA in the intestine. Exp. Anim. 54: 437-445. [Medline] [CrossRef]

26. Inoue, R., Tsukahara, T., Nakanishi, N. and Ushida, K. 2005. Development of the intestinal microbiota in the piglet. J. Gen. Appl. Microbiol. 51: 257-265. [Medline] [CrossRef]

27. Inoue, E., Akomo-Okoue, E. F., Ando, C., Iwata, Y., Judai, M., Fujita, S., Hongo, S., Nze-Nkogue, C., Inoue-Murayama, M. and Yamagiwa, J. 2013. Male genetic structure and paternity in western lowland gorillas (Gorilla gorilla gorilla). Am. J. Phys. Anthropol. 151: 583-588. [Medline] [CrossRef]

28. Ilina, L. A., Yildirim, E. A., Nikonov, I. N., Filippova, V. A., Laptev, G. Y., Novikova, N. I., Grozina, A. A., Lenkova, T. N., Manukyan, V. A., 
Egorov, I. A. and Fisinin, V. I. 2016. Metagenomic bacterial community profiles of chicken embryo gastrointestinal tract by using T-RFLP analysis. Dokl. Biochem. Biophys. 466: 47-51. [Medline] [CrossRef]

29. Kobayashi, A. and Nakamura, H. 2011. Seasonal change of food items of the Japanese rock ptarmigan. Jpn. J. Ornithol. 60: 200-215 (In Japanese with an English summary). [CrossRef]

30. Kraatz, M., Wallace, R. J. and Svensson, L. 2011. Olsenella umbonata sp. nov., a microaerotolerant anaerobic lactic acid bacterium from the sheep rumen and pig jejunum, and emended descriptions of Olsenella, Olsenella uli and Olsenella profusa. Int. J. Syst. Evol. Microbiol. 61: $795-803$. [Medline] [CrossRef]

31. Kohl, K. D., Connelly, J. W., Dearing, M. D. and Forbey, J. S. 2016. Microbial detoxification in the gut of a specialist avian herbivore, the Greater Sage-Grouse. FEMS Microbiol. Lett. 363: fnw144. [Medline] [CrossRef]

32. Langmead, B. and Salzberg, S. L. 2012. Fast gapped-read alignment with Bowtie 2. Nat. Methods 9: 357-359. [Medline] [CrossRef]

33. Li, T. H., Qin, Y., Sham, P. C., Lau, K. S., Chu, K. M. and Leung, W. K. 2017. Alterations in gastric microbiota after H. pylori eradication and in different histological stages of gastric carcinogenesis. Sci. Rep. 7: 44935. [Medline] [CrossRef]

34. López-Calleja, M. and Bonzinvic, F. 2000. Energetics and nutritional ecology of small herbivorous birds. Rev. Chil. Hist. Nat. 73: 411-420. [CrossRef]

35. Morton, E. S. 1978. Avian arboreal folivores: why not. pp. 123-130. In: The Ecology of Arboreal Folivores (Morton, E. S. ed), Smithsonian Institution Press, Washington, D.C.

36. Negro, J. J., Grande, J. M., Tella, J. L., Garrido, J., Hornero, D., Donázar, J. A., Sanchez-Zapata, J. A., BenÍtez, J. R. and Barcell, M. 2002. Coprophagy: an unusual source of essential carotenoids. Nature 416: 807-808. [Medline] [CrossRef]

37. Osawa, R., Blanshard, W. H. and Ocallaghan, P. G. 1993. Microbiological studies of the intestinal microflora of the koala, Phascolarctos-cinereus. 2. Pap, a special maternal feces consumed by juvenile koalas. Aust. J. Zool. 41: 611-620. [CrossRef]

38. Pale, A. C. 2014. LPSN-list of prokaryotic names with standing in nomenclature. http://www.bacterio.net/index.html [Accessed on March 15, 2019].

39. Pauwels, J., Taminiau, B., Janssens, G. P. J., De Beenhouwer, M., Delhalle, L., Daube, G. and Coopman, F. 2015. Cecal drop reflects the chickens' cecal microbiome, fecal drop does not. J. Microbiol. Methods 117: 164-170. [Medline] [CrossRef]

40. R Core Team. (2014). R: A language and environment for statistical computing. R Foundation for Statistical Computing, Vienna, Austria. http:// www.R-project.org/ [Accessed on March 15, 2019].

41. Redig, P. T. 1989. The avian ceca: obligate combustion chambers or facultative afterburners? -The conditioning influence of diet. J. Exp. Zool. 252: 66-69. [CrossRef]

42. Romanoff, A. L. 1960. The Avian Embryo. Structural and Functional Development. MacMillan Co., New York.

43. Sakaguchi, E. 2015. Why do rabbits ingest their feces? Sci. Rep. Fac. Agricul. Okayama Univ. 104: 23-34 (in Japanese with an English summary).

44. Soave, O. and Brand, C. D. 1991. Coprophagy in animals: a review. Cornell Vet. 81: 357-364. [Medline]

45. Stevens, C. E. and Hume, I. D. 1998. Contributions of microbes in vertebrate gastrointestinal tract to production and conservation of nutrients. Physiol. Rev. 78: 393-427. [Medline] [CrossRef]

46. Sues, H. D. 2005. Herbivory in terrestrial vertebrates: an introduction. Sues, H. D. Evolution of Herbivory in Terrestrial Vertebrates: Perspectives from the Fossil Record. Cambridge University Press, Cambridge.

47. Theberge, J. B. and West, G. C. 1973. Significance of brooding to the energy demands of Alaskan Rock Ptarmigan chicks. Arctic 26: 138-148. [CrossRef]

48. Troyer, K. 1984. Behavioral acquisition of the hindgut fermentation system by hatchling Iguana iguana. Behav. Ecol. Sociobiol. 14: 189-193. [CrossRef]

49. Tsuchida, S., Murata, K., Ohkuma, M. and Ushida, K. 2017. Isolation of Streptococcus gallolyticus with very high degradability of condensed tannins from feces of the wild Japanese rock ptarmigans on Mt. Tateyama. J. Gen. Appl. Microbiol. 63: 195-198. [Medline] [CrossRef]

50. Tsuchida, S., Ohara, Y., Kuramochi, K., Murata, K. and Ushida, K. 2017. Effective degradation of phenolic glycoside rhododendrin and its aglycone rhododendrol by cecal feces of wild Japanese rock ptarmigans. Jpn. J. Zoo Wildl. Med. 22: 41-45. [CrossRef]

51. Tsukayama, P., Boolchandani, M., Patel, S., Pehrsson, E. C., Gibson, M. K., Chiou, K. L., Jolly, C. J., Rogers, J., Phillips-Conroy, J. E. and Dantas, G. 2018. Characterization of wild and captive baboon gut microbiota and their antibiotic resistomes. mSystems 3: e00016-18. [Medline] [CrossRef]

52. Ueda, A., Kobayashi, A., Tsuchida, S., Yamada, T., Murata, K., Nakamura, H. and Ushida, K. 2018. Cecal microbiome analyses on wild Japanese rock ptarmigans (Lagopus muta japonica) reveals high level of coexistence of lactic acid bacteria and lactate-utilizing bacteria. Microorganisms $\mathbf{6}$ : 77. [Medline] [CrossRef]

53. Ulmer-Franco, A. M., Cherian, G., Quezada, N., Fasenko, G. M. and McMullen, L. M. 2012. Hatching egg and newly hatched chick yolk sac total IgY content at 3 broiler breeder flock ages. Poult. Sci. 91: 758-764. [Medline] [CrossRef]

54. Ushida, K., Kameue, C., Tsukahara, T., Fukuta, K. and Nakanishi, N. 2008. Decreasing traits of fecal immunoglobulin A in neonatal and weaning piglets. J. Vet. Med. Sci. 70: 849-852. [Medline] [CrossRef]

55. Ushida, K., Segawa, T., Tsuchida, S. and Murata, K. 2016. Cecal bacterial communities in wild Japanese rock ptarmigans and captive Svalbard rock ptarmigans. J. Vet. Med. Sci. 78: 251-257. [Medline] [CrossRef]

56. van Dongen, W. F., White, J., Brandl, H. B., Moodley, Y., Merkling, T., Leclaire, S., Blanchard, P., Danchin, E., Hatch, S. A. and Wagner, R. H. 2013. Age-related differences in the cloacal microbiota of a wild bird species. BMC Ecol. 13: 11. [Medline] [CrossRef]

57. Vicenzi, N. 2015. Phymaturus palluma (high mountain lizard) coprophagy. Herpetol. Rev. 46: 93.

58. Videnska, P., Rahman, M. M., Faldynova, M., Babak, V., Matulova, M. E., Prukner-Radovcic, E., Krizek, I., Smole-Mozina, S., Kovac, J., Szmolka, A., Nagy, B., Sedlar, K., Cejkova, D. and Rychlik, I. 2014. Characterization of egg laying hen and broiler fecal microbiota in poultry farms in Croatia, Czech Republic, Hungary and Slovenia. PLoS One 9: e110076. [Medline] [CrossRef]

59. Videvall, E., Strandh, M., Engelbrecht, A., Cloete, S. and Cornwallis, C. K. 2018. Measuring the gut microbiome in birds: Comparison of faecal and cloacal sampling. Mol. Ecol. Resour. 18: 424-434. [Medline] [CrossRef]

60. Vispo, C. and Karasov, W. H. 1997. The interaction of avian gut microbes and their host: an elusive symbiosis. pp. 116-155. In: Gastrointestinal Microbiology (Mackie, R. I., and White, B. A. eds), Springer, Boston.

61. Wagstaff, D. J. 2008. International Poisonous Plant Checklist, CRC Press, Boca Raton.

62. Wang, Q., Garrity, G. M., Tiedje, J. M. and Cole, J. R. 2007. Naive Bayesian classifier for rapid assignment of rRNA sequences into the new bacterial taxonomy. Appl. Environ. Microbiol. 73: 5261-5267. [Medline] [CrossRef]

63. Waite, D. W. and Taylor, M. W. 2014. Characterizing the avian gut microbiota: membership, driving influences, and potential function. Front. Microbiol. 5: 223. [Medline] [CrossRef]

64. West, A. G., Waite, D. W., Deines, P., Bourne, D. G., Digby, A., McKenzie, V. J. and Taylor, M. W. 2019. The microbiome in threatened species conservation. Biol. Conserv. 229: 85-98. [CrossRef]

65. Wienemann, T., Schmitt-Wagner, D., Meuser, K., Segelbacher, G., Schink, B., Brune, A. and Berthold, P. 2011. The bacterial microbiota in the ceca of Capercaillie (Tetrao urogallus) differs between wild and captive birds. Syst. Appl. Microbiol. 34: 542-551. [Medline] [CrossRef] 